\title{
Death Anxiety, Perfectionism and Disordered Eating
}

\author{
Kristina M. Le Marne and Lynne M. Harris \\ Australian College of Applied Psychology, Sydney, New South Wales, Australia
}

\begin{abstract}
Recently, death anxiety, or dread of death, has been proposed as a key transdiagnostic process underlying the anxiety disorders, depressive disorders, somatic disorders, and trauma and stressor-related disorders. In fact, it has been argued that death anxiety underlies all psychopathology, and is more fundamental than perfectionism, a process which was previously considered the root of mental illness. However, there has been a paucity of research examining the relationship between death anxiety and the eating disorders, although these conditions have been found to be strongly related to perfectionism. The present study therefore aimed to examine whether death anxiety is related to disordered eating, and whether death anxiety is a better predictor of disordered eating than perfectionism. A sample of 164 participants (132 female), average age 33.55 years $(S D=15.45$ years), completed an online survey comprising background questions (age, sex, diagnosed psychiatric disorder), the Eating Attitudes Test - 26 item version (EAT-26), the Almost Perfect Scale - Revised (APS-R), the Rosenberg Self-Esteem Scale (RSES), and the Death Anxiety Scale (DAS). The findings of a hierarchical multiple regression analysis with EAT-26 as the dependent variable, age entered at Step 1, the RSES and APS-R entered at Step 2, and the DAS entered at Step 3 showed that only death anxiety and self-esteem were independent predictors of disordered eating at Step 3. A simultaneous multiple regression analysis was subsequently run with age and the APS-R alone as predictors of EAT-26 scores. This analysis showed that perfectionism was only a predictor of disordered eating when death anxiety and self-esteem were not included in the regression model. Death anxiety and self-esteem both appear to be important transdiagnostic processes.
\end{abstract}

Keywords: death anxiety, eating disorders, perfectionism, transdiagnostic

Transdiagnostic processes refer to psychological mechanisms understood to precipitate and perpetuate psychopathology across diagnostic categories (Iverach, Menzies, $\&$ Menzies, 2014). Identifying transdiagnostic processes has been a focus of empirical research in recent years following findings that indicate limitations in the effectiveness of traditional disorder-specific interventions (see Craske \& Barlow, 2014; Ramsawh, Raffe, Edelen, Rende, \& Keller, 2009), particularly in addressing comorbid presentations (McManus, Shafran, \& Cooper, 2010). It has been argued that transdiagnostic processes provide a parsimonious explanation for the generally high comorbidity rates between mental disorders (Egan, Wade, \& Shafran, 2011) and that the persistence of symptomatology after disorder-specific treatment can be attributed to transdiagnostic processes that are not addressed in disorder-specific treatments (Brown, Antony, \& Barlow, 1995; Egan et al., 2011; Iverach et al., 2014). In fact, it has been suggested that identification of transdiagnostic constructs will lead to the development and

Address for correspondence: Professor Lynne Harris, Australian College of Applied Psychology, Level 11, 255 Elizabeth Street, Sydney NSW 2000, Australia. Email: Lynne.Harris@acap.edu.au

Behaviour Change | Volume 33 | Number 4 | 2016 | pp. 193-211 | (C) The Author(s) 2017

doi $10.1017 /$ bec.2016.11 
application of more effective psychological interventions that can address comorbid mental disorders concurrently and prevent the development of further diagnoses post-treatment, compared to disorder-specific interventions (Iverach et al., 2014). Identifying transdiagnostic processes present in eating disorders in order to improve treatment outcomes is considered particularly important, as the eating disorders are highly comorbid with depressive disorders, anxiety disorders, and personality disorders (Kaye et al., 2004; O’Brien \& Vincent, 2003; Rosenvinge, Martinussen, \& Østensen, 2000), and treatment follow-up studies indicate that the majority of patients achieve partial remission at best (Helverskov et al., 2010; Herzog et al., 1999).

Two transdiagnostic processes that have been previously identified are perfectionism (Egan et al., 2011) and perceived control (Gallagher, Naragon-Gainey, \& Brown, 2014). Cognitive behaviour therapy (CBT) interventions have been developed to target the transdiagnostic processes of perceived control and perfectionism, and these have been shown to lead to recovery from anxiety disorders in outpatient samples (Gallagher et al., 2014) and to significant concurrent decreases in anxiety, depression, and obsessionality in non-clinical samples scoring highly on measures of perfectionism (Pleva \& Wade, 2007). Moreover, a randomised controlled trial conducted by Steele and Wade (2008) that compared standard, disorder-specific CBT for bulimia nervosa to a transdiagnostic CBT-based intervention for perfectionism in the treatment of bulimia nervosa found that the two interventions yielded similar improvements in symptoms of bulimia nervosa. However, CBT for perfectionism led to greater reductions in additional symptoms of anxiety and depression compared to the disorder-specific intervention (Steele \& Wade, 2008). Findings such as these suggest that identification of transdiagnostic processes to inform the development of transdiagnostic treatment approaches may increase the efficacy, efficiency, cost-effectiveness, and generalisability of treatments for mental disorders compared to traditional diagnosis-specific interventions (Dozois, Seeds, \& Collins, 2009; Egan et al., 2011).

\section{Death Anxiety as a Transdiagnostic Process}

Death anxiety has recently been proposed as a potential transdiagnostic process (Iverach et al., 2014). Death anxiety, sometimes referred to as a 'dread' or 'fear' of death, is believed to be a universal characteristic that is important for self-preservation but which, when ineffectively managed, may become paralysing (Becker, 2014). Terror management theory provides a theoretical account of death anxiety, arguing that much of human behaviour is designed to buffer potential anxiety cued by a sense of mortality, including behaviours that do not appear to be associated with mortality (Strachan et al., 2007). For example, it is argued that death anxiety prompts individuals to create meaning and invest in cultural beliefs in order to foster a sense of purpose, self-value, and symbolic immortality to cope with the anxiety and powerlessness evoked by dread of mortality (Greenberg et al., 1992; Hayes, Schimel, Arndt, 194 \& Faucher, 2010; Iverach et al., 2014; Pyszczynski, Greenberg, \& Solomon, 1999; Routledge, 2012; Strachan et al., 2007). Indeed, fear of death has been argued to motivate the creation of symbolic language, art and music as a means of transcending the human body (Shaver \& Mikulincer, 2012).

In support of this hypothesis, studies in which participants are primed with mortality cues (questions about the individual's eventual death) or primed with neutral or aversive cues (questions about watching television or dental pain) have shown that people cued with mortality primes uniquely respond by latching onto cultural beliefs 
and personal worldviews (Solomon, Greenberg, \& Pyszczynski, 2004). For example, McGregor et al. (1998) asked students to write about their political beliefs and then gave them a bogus paragraph allegedly written by a fellow participant either supporting or attacking their political worldview. The participants were then instructed to allocate their fellow participant, who was described as disliking spicy food, an amount of hot sauce. Mortality-primed participants allocated twice as much hot sauce to perceived writers of worldview-inconsistent paragraphs compared to worldviewconsistent writers, while non-mortality-primed participants allocated roughly equal amounts. Thus, mortality salience was found to increase aggression towards those who threatened the participants' worldview.

Participants exposed to mortality cues have also been found to endorse more severe penalties to prostitutes (Rosenblatt, Greenberg, Solomon, Pyszczynski, \& Lyon, 1989); to take longer and self-report more discomfort when instructed to act disrespectfully towards culturally relevant items (e.g., using a crucifix as a hammer or sifting dye through an American flag; Greenberg, Porteus, Simon, Pyszczynski, \& Solomon, 1995); to donate more money to charity, especially those that benefit a group with which they identify (Jonas, Greenberg, \& Frey, 2003); to sit closer to same-race confederates and further away from different-race confederates (Ochsmann \& Mathy, 1994); and to increase their driving speed on a driving simulator when driving ability is seen as valuable (Taubman Ben-Ari, Florian, \& Mikulincer, 1999) Taken together, this evidence has been interpreted to mean that when primed with mortality cues, people invest in their cultural beliefs to protect themselves from death anxiety and experience greater distress when defying sociocultural norms (Greenberg et al., 1995), endorse harsher punishments for perpetrators of sociocultural violations (Rosenblatt et al., 1989), act more violently towards dissimilar others (McGregor et al., 1998), more favourably towards similar others (Jonas et al., 2003; McGregor et al., 1998; Ochsmann \& Mathy, 1994), and attempt to meet personally relevant cultural standards, even when doing so can paradoxically endanger their life (Taubman Ben-Ari et al., 1999).

\section{Death Anxiety and Psychopathology}

Following from the view that much of human behaviour is designed to protect individuals from a fear of death, death anxiety has been proposed as the 'worm at the core' of psychopathology, or the fundamental transdiagnostic process driving mental disorders (Arndt, Routledge, Cox, \& Goldenberg, 2005). Indeed, it has been argued that symptoms of mental illness result from and are exacerbated by insufficiently buffered death anxiety or maladaptive coping strategies to deal with death anxiety (Iverach et al, 2014; Maxfield, John, \& Pyszczynski, 2014; Strachan, Pyszczynski, Greenberg, \& Solomon, 2001; Strachan et al., 2007). For example, dread of death has been defined as a core feature of somatic symptom and related disorders, with patients frequently endorsing fears of bodily failure, pain, separation, and loss of control and power (Noyes, Stuart, Longley, Langbehn, \& Happel, 2002; Starcevic, 2005). Death anxiety correlates highly with hypochondriasis (Noyes et al., 2002; Starcevic, 2005), and it has been found that people with hypochondriasis disclose greater anxiety around death than healthy controls (Kellner, Abbott, Winslow, \& Pathak, 1987).

Similarly, death anxiety appears to have an important role in the anxiety disorders and in obsessive-compulsive disorder. Dread of death may be related to separation 
anxiety disorder, with separation anxiety disorder frequently involving persistent worry about losing a loved one, including through death (American Psychiatric Association, 2013). Death anxiety may also be related to agoraphobia, with a greater number of hypochondriacal concerns and a high rate of death-related catastrophe fears present in those with agoraphobia (Foa, Steketee, \& Young, 1984). Many specific phobias and obsessive-compulsive subtypes focus on injury and death, with common phobias including heights, spiders, snakes, and blood (Iverach et al., 2014); compulsive hand-washers frequently citing chronic and fatal illnesses such as HIV/AIDS as the driving force behind their anxiety and compulsive behaviours ( $\mathrm{St}$ Clare, Menzies, \& Jones, 2008); and compulsive checkers often claiming they check stoves and power points to avoid fire and death of the self or loved ones (Vaccaro, Jones, Menzies, \& St Clare, 2010). Moreover, in Strachan et al.'s (2007) series of experiments, priming mortality was found to increase phobic reactions to spiderrelated stimuli in those with spider phobia but not in those unafraid of spiders; and to increase compulsive hand-washing, measured by the amount of time spent washing hands, and the amount of soap and paper towel used, in compulsive hand-washers. In addition, priming mortality resulted in a decreased amount of time socialising compared to priming other aversive content (e.g., dental pain), particularly in those with greater social anxiety (Strachan et al., 2007). As experimentally increasing the accessibility of death-related thoughts temporally corresponds with increases in symptoms, dread of death seems to have a direct effect on mental disorders. Similarly, conceptualisations of panic disorder frequently attribute the precipitation and maintenance of panic attacks to catastrophic misappraisals of bodily sensations as 'fatal', with patients commonly reporting they think they are having a heart attack or dying on detection of a physiological change, and evidence suggesting they are hypervigilant to terms that signal physical peril, like 'pain' and 'disease' (Craske \& Barlow, 2014; Hope, Rapee, Heimberg, \& Dombeck, 1990). Moreover, reductions in these catastrophic misappraisals temporally predicts a decline in symptom severity, frequency of panic, avoidance behaviour, and distress in patients with panic disorder (Teachman, Marker, \& Clerkin, 2010). This indicates the potency of fear of death in influencing panic.

Outside of somatic concerns, the anxiety disorders and obsessive-compulsive disorder, death anxiety appears to be insufficiently buffered in those with trauma and stressor-related disorders. A study by Kesebir, Luszczynska, Pyszczynski, and Benight (2011) investigating survivors of domestic violence in Poland found that while individuals with mild or minimal trauma symptoms tend to exhibit behaviours that reflect distal defences to manage their death anxiety, such as increased worldview defence through harsher judgments of perceived moral transgressions, individuals with more severe post-traumatic stress disorder fail to exhibit the typical increased worldview defence in response to mortality priming. Furthermore, in a study of people exposed to the Ivory Coast civil war, those with a greater number of trauma symptoms

196 reported elevated death-related thoughts in response to mortality cues compared to those with fewer symptoms (Chatard et al., 2012). Findings such as these suggest that those with post-traumatic stress disorder and other trauma symptoms have difficulty managing death anxiety.

Similarly, those with depressive disorders appear to struggle with dread of death. A study of 135 psychiatric outpatients diagnosed with depressive disorders found death anxiety to be positively correlated with depression severity (Ongider \& Eyuboglu, 2013). Furthermore, two experiments manipulating mortality salience found that 
university students who were depressed responded to mortality cues with more defence of their culturally derived values than university students who were not depressed (Simon et al., 1996). This implies that greater mortality concerns may be present in people who are depressed (Iverach et al., 2014).

Importantly, preliminary treatment studies examining the effects of cognitive behavioural therapy for death anxiety have found that in people with hypochondriasis, reducing death anxiety has been associated with a decrease in hypochondriasis, increased cultural worldview investment and self-esteem, and an improvement in general psychological wellbeing in the form of greater self-reported life satisfaction, the development of life goals, and attempts to live a healthier lifestyle (Furer \& Walker, 2008; Hiebert, Furer, McPhail, \& Walker, 2005). Similarly, Menzies, Menzies, and Iverach (2015) highlight two case reports of patients with current obsessive-compulsive disorder and a long history of other psychiatric conditions. Through targeting an underlying fear of death in treatment, these patients experienced a normalisation in mood and significant improvement in their obsessions and compulsions. If treating death anxiety can improve psychopathology and indicators of mental wellbeing, this supports the notion that dread of death is causally related to mental illness.

The findings reviewed above implicate death anxiety as an important transdiagnostic process in somatic disorders (Kellner et al., 1987; Noyes et al., 2002; Starcevic, 2005), anxiety disorders (Craske \& Barlow, 2014; Foa et al., 1984; Hope et al., 1990; Iverach et al., 2014; St Clare et al., 2008; Strachan et al., 2007; Teachman et al., 2010; Vaccaro et al., 2010), trauma and stressor-related disorders (Chatard et al., 2012; Kesebir et al., 2011), and depressive disorders (Iverach et al., 2014; Ongider \& Eyuboglu, 2013; Simon et al., 1996). However, little research into the relationship between death anxiety and eating disorder symptomology has been conducted.

\section{Death Anxiety in the Eating Disorders}

Collectively, the eating disorders, specifically anorexia nervosa, bulimia nervosa, and binge-eating disorder, are characterised by persisting disturbances in eating behaviours that culminate in impairments in physical and psychosocial functioning (American Psychiatric Association, 2013). Notably, many people exhibit dysfunctional eating attitudes and behaviours, or eating disorder symptoms, without meeting full clinical criteria for an eating disorder diagnosis (Striegel-Moore et al., 2009). Although in the past there have been references to death anxiety and preoccupation with death as potential aetiological and maintaining factors in anorexia nervosa (Binswanger, 1945; Langdon-Brown, Crookshank, Young, Gordon, \& Bevan-Brown, 1931), in general, there has been a paucity of research into the relationship between death anxiety and the eating disorders, or even general eating disorder symptomology. However, there has been some recent speculation into this link. In their review article, Alantar and Maner (2008) proposed that a fear of gaining weight, as present in anorexia nervosa and bulimia nervosa or subclinical eating disorder symptoms, may protect people and serve as a distraction from a fear of death. They additionally posit that greater struggles with dread of death in youth may be a risk factor for eating psychopathology. Meanwhile, in Farber, Jackson, Tabin, and Bachar's (2007) article, which presents a case of a patient with chronic anorexia nervosa and a case of a patient with bulimia nervosa, the authors argue that people with eating disorders frequently have a preoccupation with death and annihilation, and that in the instance of treatment-refractory 
patients, the role of death anxiety in their individual presentations may need to be addressed.

While few studies have directly examined the relationship between death anxiety and eating disorder symptomology, there is some empirical evidence to suggest dread of death may underlie the omnipresent overvaluation of weight and shape and the associated cognition and behaviours in disordered eating (Giles, 1995; Goldenberg, Arndt, Hart, \& Brown, 2005). Goldenberg et al. (2005) conducted three experiments with non-clinical samples and found that women who were primed for mortality salience perceived themselves as further away from their ideal thinness, restricting their consumption of high-calorie nutritious foods more than women primed for dental pain. Further, Giles (1995) examined 31 women who met criteria for anorexia nervosa and who had not experienced any purging episodes in the past three months, and 31 control participants matched for age, gender, ethnicity, and socioeconomic status. Those with anorexia nervosa had significantly greater death anxiety towards themselves and others compared to controls. This supports a relationship between eating disorder symptomology and death anxiety.

It may seem paradoxical to suggest death anxiety as a transdiagnostic process in the eating disorders, given that anorexia nervosa has the highest mortality rate of all mental disorders (Farber et al., 2007), and that people with eating disorders frequently deny concerns about their life-threatening behaviours (Farber, 2000). However, it has been argued that those with eating disorders and those with subclinical eating disorder symptoms turn to body weight and shape for identity and meaning, to defend against feelings of powerlessness and an inability to control their environment (Bruch, 1978; Egan et al., 2014; Russell, Halasz, \& Beumont, 1990; Slade, 1982). As death anxiety can instil feelings of powerlessness and lack of control, and individuals act in ways that provide identity and meaning to buffer an underlying dread of death (Iverach et al., 2014; Noyes et al., 2002; Strachan et al., 2007; Yalom, 2008), death anxiety may play an important role in eating psychopathology. Circumstantially, the fact that low self-esteem is a core feature of multiple eating disorders (Fairburn, Cooper, \& Shafran, 2003) and elevated self-esteem can act as a buffer for death anxiety (Greenberg, 2012; Greenberg et al., 1992) may suggest that individuals with disordered eating attitudes and behaviours may be particularly vulnerable to death anxiety mismanagement. Further, as thinness is culturally valued in Western societies, people may be existentially motivated to control their body weight and shape (Goldenberg et al., 2005). As the physical body represents mortality, applying cultural standards of weight and shape to it may convert the body from a reminder of death to a protection against death anxiety (Goldenberg, Pyszczynski, Greenberg, \& Solomon, 2000). Indeed, two experiments by Goldenberg, McCoy, Pyszczynski, Greenberg, and Solomon (2000) found that when mortality was made salient, those who derived self-worth from their appearance increased their identification with aspects of their physical bodies for which they believed they were successfully meeting cultural standards, and reported a greater desire for bodily activity, specifically the physical aspects of sexual intercourse. This implies that the body can become a form of defence against dread of death when sociocultural standards of beauty are met, and people, including those with disordered eating, may be motivated to value and attempt to control their weight and shape in order to buffer an underlying fear of death. Though a connection between death anxiety and eating psychopathology may initially appear counter-intuitive, a preliminary study thoroughly examining whether death anxiety as a transdiagnostic process extends to eating disorder symptomology is warranted. 


\section{Death Anxiety, Perfectionism and Eating Disorders}

Notably, prior transdiagnostic processes investigated in the context of disordered eating include low self-esteem, interpersonal difficulties, mood intolerance, and perfectionism (Fairburn et al., 2003). Perfectionism, in particular, which is characterised by the continual striving to reach high standards and the over-dependence of selfworth on achievement (Egan et al., 2011; Egan, Wade, Shafran, \& Antony, 2014; Riley \& Shafran, 2005), has been well established as a transdiagnostic process in eating disorders. Indeed, perfectionism has prospectively been shown to predict the emergence of bulimic symptoms in female students (Steele, Corsini, \& Wade, 2007), and retrospective reports suggest childhood perfectionism is linked to the development of eating disorders, including bulimia nervosa and anorexia nervosa (Fairburn, Cooper, Doll, \& Welch, 1999; Fairburn, Welch, Doll, Davies, \& O'Connor, 1997; Southgate, Tchanturia, Collier, \& Treasure, 2008). In fact, perfectionism has previously been argued to be the fundamental transdiagnostic process driving all psychopathology. Indeed, findings suggest that perfectionism is typically elevated in people with eating disorders, obsessive-compulsive disorder, and major depressive disorder compared to healthy controls, that greater pretreatment levels of perfectionism are indicative of a poorer prognosis, and that treating perfectionism yields large reductions in symptoms of anxiety, depression, obsessionality, and disordered eating (Egan et al., 2011; Egan et al., 2014). However, the emerging evidence for death anxiety as a fundamental transdiagnostic process in somatic disorders (Kellner et al., 1987; Noyes et al., 2002; Starcevic, 2005), anxiety disorders (Craske \& Barlow, 2014; Foa et al., 1984; Hope et al., 1990; Iverach et al., 2014; St Clare et al., 2008; Strachan et al., 2007; Teachman et al., 2010; Vaccaro et al., 2010), trauma and stressor-related disorders (Chatard et al., 2012; Kesebir et al., 2011) and depressive disorders (Iverach et al., 2014; Ongider \& Eyuboglu, 2013; Simon et al., 1996), and treatment follow-up studies showing that the majority of patients with eating disorders only achieve partial remission when perfectionism is addressed in treatment, with many patients developing other diagnoses (Helverskov et al., 2010; Steinhausen, 2009; Turner, Marshall, Stopa, \& Waller, 2015), challenges the argument that perfectionism is the fundamental transdiagnostic process for all mental disorders, including eating disorders.

An alternative view is that perfectionism may be related to death anxiety. Similar to terror management theory's proposition that individuals strive to create self-purpose and self-value to buffer death anxiety, perfectionistic individuals usually turn to an area of life that offers them a sense of accomplishment and control, such as weight and shape in the eating disordered patient (Egan et al., 2014). In this sense, there is conceptual overlap between death anxiety and perfectionism in fastidiously striving to create meaning. Interestingly, in a series of randomised, controlled trials, Kesebir (2014) found that humility, defined as a willingness to accept one's limits and low levels of selffocus - which may be understood as the opposite of the high standards and focus on personal achievement inherent in perfectionism - was inversely associated with death anxiety. Specifically, priming humility decreased death anxiety, and only individuals low in humility experienced increased death anxiety in response to mortality cues (Kesebir, 2014).

In line with Strachan et al. (2007), it is possible that perfectionism is an unreliable or maladaptive method of coping with death anxiety that causes psychopathology by inefficiently buffering dread of death. Indeed, perfectionism, when high standards and goals are met, can produce positive emotional consequences, such as bolstered self-esteem and feelings of self-efficacy, while failing to meet goals culminates in 
self-criticism, shame, guilt, and low mood (e.g., Bieling, Israeli, \& Antony, 2004; DiBartolo, Li, \& Frost, 2008; Rhéaume et al., 2000). Based on the theoretical connection between death anxiety and perfectionism, it is possible that perfectionism is not a fundamental transdiagnostic process but merely a product of, or a mechanism to deal with, an underlying dread of death. If death anxiety is the fundamental transdiagnostic process across psychiatric disorders, death anxiety should be a better predictor of mental health outcomes such as disordered eating than perfectionism, a well-established transdiagnostic process in eating psychopathology.

\section{Aim}

The aim of the current study was to examine the relationship between death anxiety, perfectionism and eating disorder symptoms in a general population sample. Specifically, it was hypothesised that:

- death anxiety will be positively associated with eating disorder symptomology;

- death anxiety will be positively associated with perfectionism;

- death anxiety will be a better predictor of eating disorder symptomology than perfectionism.

As high self-esteem acts as a buffer against death anxiety and low self-esteem is related to more disordered eating, self-esteem was included in the study as a control variable and it was hypothesised that:

- self-esteem will be negatively associated with death anxiety;

- self-esteem will be negatively associated with eating disorder symptomology.

\section{Method}

\section{Participants}

Participants were recruited from an advertisement promoted on the social media website Facebook, as well as on the Centre for Eating and Dieting Disorders website. Participants were Australian residents of at least 18 years of age and were not required to have a diagnosed eating disorder. A total of 164 participants, $132(80.5 \%)$ females and $32(19.5 \%)$ males aged from 18 to 71 years $(M=33.55$; $S D=15.45)$ completed the study. A total of 65 participants (39.6\%) self-reported a current mental disorder diagnosis, and 25 participants (15.2\%) self-reported a current eating disorder diagnosis.

\section{Measures}

Background questions. Participants were asked to report their age, gender, whether they had a current diagnosed mental disorder, and whether they had a current diagnosed eating disorder.

\section{Eating Attitudes Test - 26 (EAT-26; Garner, Olmstead, Bohr, E Garfinkel,} 1982). The EAT-26 is a shortened 26-item version of the 40 -item EAT, which was designed to screen for eating disorder symptoms. For each item, participants rate their agreement on a 6-point scale ranging from always to never. Excluding the final item, which is reverse-scored, each always item receives a score of 3; each usually item yields a score of 2; each often item is scored as a 1; and each item rated sometimes, rarely or never is scored as a 0 , so that total scores range from 0 to 78 . Higher scores on the EAT-26 indicate greater eating disturbance, with a score of 20 or above indicating need for referral for further assessment. The EAT-26 is highly correlated with the EAT 
$(r=.98)$ and has good test-retest reliability (Carter $\&$ Moss, 1984), adequate internal consistency (Cronbach's alpha $=.86$; Gleaves, Pearson, Ambwani, \& Morey, 2014), and good convergent validity (Doninger, Enders, \& Burnett, 2005). The EAT-26 additionally has good sensitivity and adequate specificity for eating disorders (Garner et al., 1982).

Rosenberg Self-Esteem Scale (RSES; Rosenberg, 1965). The RSES consists of 10 statements that measure self-esteem using a 4-point Likert scale, ranging from strongly agree to strongly disagree. Scores for each positively keyed item range from 3 (strongly agree) to 0 (strongly disagree), with total scores on the RSES ranging from 0 to 30 . Higher scores on the RSES indicate higher self-esteem, or a greater perception of self-worth, with healthy self-esteem indicated by a score between 15 and 25 . The RSES is a simple, widely used measure, with recognised face validity (Sinclair et al., 2010), structural and predictive validity, internal consistency and test-retest reliability (Schmitt \& Allik, 2005; Torrey, Mueser, McHugo, \& Drake, 2000).

Almost Perfect Scale - Revised (APS-R; Slaney, Rice, Mobley, Trippi, Ë Ashby, 2001). The APS-R is a 23-item measure of perfectionism, consisting of three factors (High Standards, Order, and Discrepancy). Items are scored on a 7-point Likert scale that ranges from 1 (strongly disagree) to 7 (strongly agree). The APS-R possesses good construct validity, and adequate overall internal consistency, with Cronbach's alpha for each subscale ranging from .82 to .92 (Slaney et al., 2001). Higher scores overall indicate greater perfectionism.

Death Anxiety Scale (DAS; Templer, 1970). The DAS is a forced choice, 15-item measure of death anxiety, where each positively keyed item is scored 1 (true) or 0 (false), such that total scores on the DAS range from 0 to 15 . Translated into multiple languages, it has been established as a reliable and valid measure of death anxiety, yielding good convergent validity, and adequate test-retest correlations and internal consistency estimates (Abdel-Khalek, 2004; Royal \& Elahi, 2011; Tomás-Sábado \& Gomez-Benito, 2002). Higher scores on the DAS are indicative of greater death anxiety.

\section{Procedure}

The study was approved by the Navitas Professional Institute Human Research Ethics Committee. Participants completed all measures through an online survey that they accessed through a link from an advertisement. Participants read information about the study and those who consented to participate confirmed that they were current Australian residents over 18 years of age before being directed to the survey. Participants first entered their age and gender and then completed the EAT-26, the Rosenberg Self-Esteem Scale, the APS-R, and the DAS in that order. Participants were asked whether they had a currently diagnosed mental disorder, whether they had a currently diagnosed eating disorder, and were then debriefed. As an incentive for completing the study, participants were offered to go into a draw to receive one of four AU\$100 JB Hi-Fi vouchers.

\section{Data Analysis}

All analyses were run using the IBM SPSS Statistics v23.0 Graduate Pack. 


\section{TABLE 1}

Descriptive Statistics and Zero-Order Correlations for Gender, Age, EAT-26 Scores, RSES Scores, DAS Scores, APS-R Scores, Self-Reported Mental Disorder Diagnostic Status and Self-Reported Eating Disorder Diagnostic Status

\begin{tabular}{lcccccccc}
\hline & $M(S D)$ & 1 & 2 & 3 & 4 & 5 & 6 & 7 \\
\hline 1. Gender $^{\mathrm{a}}$ & $132(80.49)^{\mathrm{b}}$ & & & & & & & \\
2. Age & $33.55(15.45)$ & $.21^{* *}$ & & & & & & \\
3. EAT-26 & $11.61(13.14)$ & .15 & $-.19^{*}$ & & & & & \\
4. RSES & $17.30(6.45)$ & -.14 & $.16^{*}$ & $-.57^{* *}$ & & & & \\
5. DAS & $6.90(3.73)$ & .13 & -.04 & $.46^{* *}$ & $-.36^{* *}$ & & & \\
6. APS-R & $106.86(22.76)$ & .08 & $-.17^{*}$ & $.46^{* *}$ & $-.63^{* *}$ & $.30^{* *}$ & & \\
7. SRMD & $65(39.63)^{\mathrm{b}}$ & $.21^{* *}$ & -.02 & $.49^{* *}$ & $-.49^{* *}$ & $.37^{* *}$ & $.35^{* *}$ & \\
8. SRED & $25(15.24)^{\mathrm{b}}$ & .15 & $-.16^{*}$ & $.82^{* *}$ & $-.49^{* *}$ & $.36^{* *}$ & $.35^{* *}$ & $.52^{* *}$ \\
\hline
\end{tabular}

Note: SRMD = self-reported mental disorder; SRED = self-reported eating disorder.

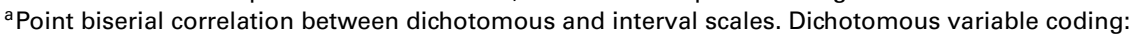

Gender (Female =1, Male =0); $\operatorname{SRMD}($ Yes = 1, No =0); $\operatorname{SRED}($ Yes $=1$, No =0).

${ }^{\text {b }}$ Number coded as ' 1 '; percentage.

** Correlation is significant at the .01 level (two-tailed); ${ }^{*}$ Correlation is significant at the .05 level (two-tailed)

\section{Results}

The correlations between the DAS, EAT-26, RSES, age, gender, and self-reported mental and eating disorder diagnoses are presented in Table 1. As predicted, DAS scores were positively correlated with EAT-26 scores, self-reported mental and eating disorder diagnoses, and negatively correlated with RSES scores. Additionally, as expected, EAT-26 scores were highly correlated with self-reported eating disorder diagnoses and negatively correlated with RSES scores; APS-R scores were positively correlated with self-reported mental and eating disorder diagnoses and negatively correlated with RSES scores; and RSES scores were negatively correlated with selfreported diagnoses.

To examine the contribution of death anxiety to eating disorder symptomology compared to perfectionism and self-esteem, a hierarchical multiple regression was conducted with EAT-26 scores as the dependent variable, and DAS, APS-R and RSES scores, as well as age, as predictors. Only variables that were correlated with EAT-26 were included as predictors (Tabachnick \& Fidell, 2014). The sample size $(N=164)$ was above the minimum recommended by Tabachnick and Fidell (2014) for multiple regression analysis with four predictor variables (minimum $N=108$ ). The data were screened for outliers, multicollinearity, normality, linearity, and homoscedasticity of residuals, following the guidelines of Tabachnick and Fidell (2014). The EAT-26 violated the parametric assumption of homoscedasticity. Using a square-root transformation eliminated heteroscedasticity; however, this made the results of the regression difficult to interpret. As repeating the multiple regression analysis with the transformed EAT-26 variable yielded the same pattern of results as the analysis with the untransformed variable, and Tabachnick and Fidell (2014) note that heteroscedasticity does not invalidate a regression analysis but weakens uncovered relationships, the analysis with the untransformed variable is presented here for ease of interpretation. 
TABLE 2

Sequential Regression Model for Variables Predicting Disordered Eating

\begin{tabular}{cccccc}
\hline & $\mathrm{R}^{2}$ & $\Delta \mathrm{R}^{2}$ & $\mathrm{~b}$ & $\mathrm{SE}_{\mathrm{b}}$ & $\beta$ \\
\hline Step 1 & .036 & .036 & & & \\
Age & & & $-.16^{*}$ & .07 & -.19 \\
Step 2 & .344 & .308 & & & \\
Age & & & -.08 & .06 & -.09 \\
RSES & & $-.92^{* *}$ & .17 & -.45 \\
APS-R & & .09 & .05 & .16 \\
Step 3 & .414 & .071 & & & \\
Age & & & -.08 & .05 & -.10 \\
RSES & & & $-.76^{* *}$ & .16 & -.37 \\
APS-R & & & .07 & .05 & .12 \\
DAS & & & $.01^{* *}$ & .23 & .29 \\
\hline
\end{tabular}

Note: ${ }^{* *}$ Coefficients are significant at the 0.01 level (two-tailed); ${ }^{*}$ Coefficients are significant at the 0.05 level (two-tailed).

Age was entered at Step 1, the RSES and APS-R were entered at Step 2, and the DAS was entered at Step 3. As shown in Table 2, at step 1, age accounted for 3.6\% of the variance in EAT-26 scores and contributed significantly to the regression model, $F(1,162)=6.01, p<.05$. Introducing the RSES and APS-R at step 2 explained an additional $30.8 \%$ of the variance in EAT scores, and this change in $R^{2}$ was significant, $F(2,160)=37.55, p<.001$. Adding the DAS at step 3 explained an additional $7.1 \%$ of the variance in EAT-26, and this change in $R^{2}$ was significant, $F(1,159)=$ $19.15, p<.001$. The overall multiple regression model was significant, with DAS, APS-R, and RSES scores and age explaining $41.4 \%$ of the variance in EAT-26 scores, $F(4,159)=28.12, p<.001$. As shown in Table 2 , in the final model only the DAS and RSES significantly predicted EAT-26 scores, uniquely explaining $7.1 \%$ and $7.9 \%$ of the variance in EAT-26 scores respectively. Controlling for the APS-R, RSES, and age for every extra point score on the DAS, EAT-26 scores increased by $1.01, b=$ $1.01, \mathrm{SE}_{b}=.23, \beta=.29, p<.001[95 \% \mathrm{CI}=.55,1.46]$. Similarly, controlling for the DAS, APS-R and age, for every extra point score on the RSES, EAT-26 scores decreased by $0.76, b=-.76, \mathrm{SE}_{b}=.16, \beta=-.37, p<.001[95 \% \mathrm{CI}=-1.08$, -.44]. Thus, DAS was positively associated with EAT-26, and RSES was negatively associated with EAT-26.

Post-hoc, a simultaneous multiple regression was run with only age and APS-R as predictors to investigate whether APS-R was a significant predictor of EAT-26 when DAS and RSES were excluded from the regression model. Together, age and APS-R accounted for $22.0 \%$ of the variance in EAT-26, $F(2,161)=22.77, p<.001$. APS-R was a significant predictor of EAT-26, uniquely explaining $18.5 \%$ of the variance in EAT-26.

\section{Discussion}

This study investigated the relationship between death anxiety, disordered eating, and perfectionism. Based on the previous findings supporting death anxiety as a trans- 
diagnostic construct that may be involved in eating disorder symptomology and that perfectionism may be an unreliable method of coping with death anxiety, it was predicted that death anxiety would be positively associated with eating disorder symptomology and perfectionism, and that death anxiety would be a better predictor of eating disorder symptomology than perfectionism. As expected, it was found that greater death anxiety was associated with greater eating disturbance, greater perfectionism, and self-reports of a current mental disorder or eating disorder. Moreover, after controlling for self-esteem, age and perfectionism, death anxiety remained a significant predictor of eating disorder symptomology. Therefore, the current findings are consistent with the view that death anxiety is a transdiagnostic process that underlies symptomology associated with disordered eating (Giles, 1995; Goldenberg et al., 2005; Iverach et al., 2014), as well as symptomology associated with somatic disorders (Kellner et al., 1987; Noyes et al., 2002; Starcevic, 2005), anxiety disorders (Craske \& Barlow, 2014; Foa et al., 1984; Hope et al., 1990; Iverach et al., 2014; St Clare et al., 2008; Strachan et al., 2007; Teachman et al., 2010; Vaccaro et al., 2010), trauma and stressor-related disorders (Chatard et al., 2012; Kesebir et al., 2011), and depressive disorders (Iverach et al., 2014; Ongider \& Eyuboglu, 2013; Simon et al., 1996).

Perfectionism has been proposed as a fundamental transdiagnostic process in major depressive disorder, obsessive-compulsive disorder, and the eating disorders (Egan et al., 2011; Egan et al., 2014), and interventions specifically targeting perfectionism have been found to be effective in treating bulimia nervosa and co-occuring symptoms of anxiety and depression in a clinical sample (Steele \& Wade, 2008), and in treating anxiety, depression and obsessionality in a non-clinical sample (Pleva \& Wade 2007). Similarly, self-esteem has been implicated as a transdiagnostic process in the eating disorders (Fairburn et al., 2003). Importantly, while perfectionism was associated with disordered eating and with self-reports of a current mental or eating disorder in the present study, perfectionism was not a significant, independent predictor of eating disorder symptomology when self-esteem, age, and death anxiety were controlled. Thus, the current findings are inconsistent with the wealth of literature concerning perfectionism as a key transdiagnostic process particularly implicated in disordered eating. However, self-esteem was a significant, independent predictor of eating disorder symptomology when age, death anxiety, and perfectionism were controlled consistent with earlier research (e.g., Fairburn, Cooper, \& Shafran, 2008).

Since perfectionism was found to be significantly correlated with death anxiety and self-esteem in this study but was not a significant predictor of disordered eating with self-esteem and death anxiety in the model, this suggests that perfectionism was not uniquely accounting for variability in disordered eating. To our knowledge, no study to date has examined the unique contribution of perfectionism, self-esteem, and death anxiety in predicting eating disorder symptomology, and it is possible that previously reported findings concerning the relationship between effects of perfectionism on psychopathology (e.g., Egan et al., 2011; Egan et al., 2014; Southgate et al., 2008; 204 Steele et al., 2007) are a result of the omission of death anxiety from these studies. If, in line with Strachan et al. (2007), perfectionism is a maladaptive method of coping with death anxiety through fastidiously striving to create meaning, and death anxiety is the fundamental transdiagnostic process underlying psychopathology (Arndt et al., 2005; Iverach et al., 2014; Maxfield et al., 2014), then arguably when death anxiety is not directly assessed and included in analyses, perfectionism may be acting as a proxy measure of death anxiety. Similarly, the effectiveness of treatments aimed at perfectionism in reducing symptomology (Egan et al., 2011; Egan et al., 2014; Pleva \& 
Wade, 2007; Steele \& Wade, 2008) may be due to these interventions reducing the use of ineffective methods to cope with death anxiety. Consistent with this interpretation, the findings of the post-hoc simultaneous multiple regression reported here indicated that perfectionism was a significant predictor of disordered eating when self-esteem and death anxiety were not included in the model, but that adding death anxiety and self-esteem eliminated the effects of perfectionism on disturbed eating.

The finding that self-esteem is a unique predictor of disturbed eating challenges the assumption that death anxiety is the key transdiagnostic process accounting for psychopathology (Arndt et al., 2005; Iverach et al., 2014), at least for disordered eating. Indeed, the findings of the present study provide support for death anxiety and self-esteem as related but independent predictors of eating disturbance. Selfesteem has been proposed as a transdiagnostic process for disordered eating (Fairburn et al., 2008). Low self-esteem is related to increased eating disorder severity (Beren \& Chrisler, 1990), the presence of early-onset anorexia nervosa (Lask \& BryantWaugh, 1992), bulimia nervosa (Cooper \& Fairburn, 1993), binge-eating disorder (Mitchell \& Mussell, 1995), obesity (de Zwaan et al., 1994), abnormal eating attitudes (Fisher, Schneider, Pegler, \& Napolitano, 1991) and concerns with body image (Foster, Waddan, \& Vogt, 1997). There is also evidence that self-esteem is important in depressive disorders (Orth, Robins, \& Meier, 2009; Sowislo, Orth, \& Meier, 2014) and in obsessive-compulsive disorder, social phobia, specific phobia, and overanxious disorder (Maldonado et al., 2013). Low self-esteem is also associated with greater anxiety or affective comorbidity in people diagnosed with schizophrenia (Karatzias, Gumley, Power, \& O'Grady, 2007). Self-esteem, along with death anxiety, merits further investigation as a unique and fundamental transdiagnostic construct beyond the eating disorders.

Several limitations of this study must be recognised. First, the study was crosssectional so that no causal inferences can be made. Second, while many participants $(15.2 \%)$ self-reported eating disorder diagnoses, there was no independent verification of these diagnoses and the sample must be considered a non-clinical sample. A large, strictly clinical sample would strengthen the present findings. Third, as participants completed the questionnaires online, the identity of respondents could not be verified and it is possible that responses were not honest. However, there would be little motivation for an individual to complete the survey dishonestly, and it is also possible that the anonymity of the online methodology reduced the likelihood of response bias towards socially acceptable responses. Further research is also needed to clarify the status of perfectionism, self-esteem, and death anxiety as transdiagnostic processes accounting for psychopathology. If, as argued here, death anxiety and self-esteem largely account for the effects of perfectionism, then this implies that transdiagnostic interventions should focus on these variables rather than perfectionism. As implied by Iverach et al. (2014), better targeted treatments have the potential to assist those who do not respond to standard treatments. Since death anxiety has only recently gained attention as a transdiagnostic process, it is still unclear how death anxiety would be best targeted in the treatment of eating disorders. Menzies et al. (2015) speculate that several therapies that focus on increasing a personal sense of meaning and replacing maladaptive coping strategies for dealing with death anxiety could be used to address an underlying dread of death in people with mental disorders. Menzies et al. (2015) specifically emphasise existential psychotherapy, which has recently been used to treat bipolar disorder (Goldner-Vukov, Moore, \& Cupina, 2007), panic disorder (Randall, 2001), and depression (Stalsett, Gude, Ronnestad, \& Monsen, 2012); existential- 
humanistic therapies, such as dignity therapy and meaning-centred therapy, which have been found to be moderately successful in alleviating death anxiety in terminally ill patients (Breitbart et al., 2000; Chochinov, Hack, Hassard, \& Kristjanso, 2004); and cognitive behavioural approaches drawing on elements of existential and existentialhumanistic therapies to build a sense of agency and meaning, as well as helpful coping strategies, which have previously been found to improve mental wellbeing (Furer \& Walker, 2008; Hiebert et al., 2005). Further research into the most effective death anxiety interventions would be beneficial.

In sum, death anxiety has been recently proposed to be the 'worm at the core' of psychopathology. This study was the first to examine the role of death anxiety in eating disorder symptomology compared to the recognised transdiagnostic processes, perfectionism, and self-esteem. Replication of the current study, both with a large general population sample and clinical samples, should be undertaken to strengthen the present results, and extending the methodology to compare death anxiety, perfectionism, and self-esteem as predictors of treatment response may be warranted. Longitudinal, prospective studies investigating whether greater death anxiety and lower self-esteem predict the later development of eating or other mental disorders; and randomised controlled trials comparing the effectiveness of treatments directly addressing perfectionism versus those addressing death anxiety and those addressing core low self-esteem could be of particular value.

\section{References}

Abdel-Khalek, A.M. (2004). The Arabic scale of death anxiety (ASDA): Its development, validation, and results in three Arab countries. Death Studies, 28, 435-457.

Alantar, Z., \& Maner, F. (2008). Eating disorders in the context of attachment theory. Anatolian Journal of Psychiatry, 9, 97-104.

American Psychiatric Association. (2013). Diagnostic and statistical manual of mental disorders: DSM-V. Washington, DC: American Psychiatric Association.

Arndt, J., Routledge, C., Cox, C.R., \& Goldenberg, J.L. (2005). The worm at the core: A terror management perspective on the roots of psychological dysfunction. Applied and Preventive Psychology, $11,191-213$.

Becker, E. (2014). The terror of death. In The denial of death (pp. 45-66). New York, NY: Souvenir Press.

Beren, S.E., \& Chrisler, J.C. (1990). Gender role, need for approval, childishness, and self-esteem: Markers of disordered eating?. Research Communications in Psychology, Psychiatry $\mathcal{E}$ Behaviour, 15, 183-198.

Bieling, P.J., Israeli, A.L., \& Antony, M.M. (2004). Is perfectionism good, bad, or both? Examining models of the perfectionism construct. Personality and Individual Differences, 36, 1373-1385.

Binswanger, L. (1945). The case of Ellen West: An anthropological-clinical study. In R. May, E. Angel, H. Ellenberger (Eds.), W. Mendel \& J. Lyons (Trans.), Existence: A new dimension in psychiatry and psychology (pp. 237-364). New York: Basic Books.

Breitbart, W., Rosenfeld, B., Pessin, H., Kaim, M., Funesti-Esch, J., Galietta, M., \& Brescia, R. (2000). Depression, hopelessness, and desire for hastened death in terminally ill patients with cancer. Journal of the American Medical Association, 284, 2907-2911.

Brown, T.A., Antony, M.M., \& Barlow, D.H. (1995). Diagnostic comorbidity in panic disorder: Effect on treatment outcome and course of comorbid diagnoses following treatment. Journal of Consulting and Clinical Psychology, 63, 408-418.

Bruch, H. (1978). The golden cage: The enigma of anorexia nervosa. Cambridge, MA: Harvard University Press. 
Carter, P.I., \& Moss, R.A. (1984). Screening for anorexia and bulimia nervosa in a college population: Problems and limitations. Addictive Behaviours, 9, 417-419.

Chatard, A., Pyszczynski, T., Arndt, J., Selimbegović, L., Konan, P.N., \& Van der Linden, M. (2012). Extent of trauma exposure and PTSD symptom severity as predictors of anxiety-buffer functioning. Psychological Trauma: Theory, Research, Practice, and Policy, 4, 47-55.

Chochinov, H.M., Hack, T., Hassard, T., \& Kristjanson, L.J. (2004). Dignity and psychotherapeutic considerations in end-of-life care. Journal of Palliative Care, 20, 134-142.

Cooper, P.J., \& Fairburn, C.G. (1993). Confusion over the core psychopathology of bulimia nervosa. International Journal of Eating Disorders, 13, 385-389.

Craske, M.G., \& Barlow, D.H. (2014). Panic disorder and agoraphobia. In D.H. Barlow (Ed.), Clinical handbook of psychological disorders (5th ed.). New York, NY: Guilford Publications.

DiBartolo, P.M., Li, C.Y., \& Frost, R.O. (2008). How do the dimensions of perfectionism relate to mental health?. Cognitive Therapy and Research, 32, 401-417.

de Zwaan, M., Mitchell, J.E., Seim, H.C., Specker, S.M., Pyle, R.L., Raymond, N.C., \& Crosby, R.B. (1994). Eating related and general psychopathology in obese females with binge eating disorder. International Journal of Eating Disorders, 15, 43-52.

Doninger, G.L., Enders, C.K., \& Burnett, K.F. (2005). Validity evidence for Eating Attitudes Test scores in a sample of female college athletes. Measurement in Physical Education and Exercise Science, 9, 35-49.

Dozois, D.J., Seeds, P.M., \& Collins, K.A. (2009). Transdiagnostic approaches to the prevention of depression and anxiety. Journal of Cognitive Psychotherapy, 23, 44-59.

Egan, S.J., Wade, T.D., \& Shafran, R. (2011). Perfectionism as a transdiagnostic process: A clinical review. Clinical Psychology Review, 31, 203-212.

Egan, S.J., Wade, T.D., Shafran, R., \& Antony, M.M. (2014). Cognitive-behavioural treatment of perfectionism. New York, NY: Guilford Publications.

Fairburn, C.G., Cooper, Z., Doll, H.A., \& Welch, S.L. (1999). Risk factors for anorexia nervosa: three integrated case-control comparisons. Archives of General Psychiatry, 56, 468476.

Fairburn, C.G., Cooper, Z., \& Shafran, R. (2003). Cognitive behaviour therapy for eating disorders: A 'transdiagnostic' theory and treatment. Behaviour Research and Therapy, 41, 509-528.

Fairburn, C.G., Cooper, Z., \& Shafran, R. (2008). Enhanced cognitive behaviour therapy for eating disorders ('CBT-E'): An overview. In C.G. Fairburn (Ed.), Cognitive behaviour therapy and eating disorders (pp. 23-34). New York, NY: Guilford Press.

Fairburn, C.G., Welch, S.L., Doll, H.A., Davies, B.A., \& O'Connor, M.E. (1997). Risk factors for bulimia nervosa: A community-based case-control study. Archives of General Psychiatry, 54, 509-517.

Farber, S. (2000). When the body is the target: Self-harm, pain, and traumatic attachments. Northvale, NJ: Jason Aronson.

Farber, S.K., Jackson, C.C., Tabin, J.K., \& Bachar, E. (2007). Death and annihilation anxieties in anorexia nervosa, bulimia, and self-mutilation. Psychoanalytic Psychology, 24, 289-305.

Fisher, M., Schneider, M., Pegler, C., \& Napolitano, B. (1991). Eating attitudes, health-risk behaviours, self-esteem, and anxiety among adolescent females in a suburban high school. Journal of Adolescent Health, 12, 377-384.

Foa, E.B., Steketee, G., \& Young, M.C. (1984). Agoraphobia: Phenomenological aspects, associated characteristics, and theoretical considerations. Clinical Psychology Review, 4, 431-457.

Foster, G.D., Wadden, T.A., \& Vogt, R.A. (1997). Body image in obese women before, during, and after weight loss treatment. Health Psychology, 16, 226-229.

Furer, P., \& Walker, J.R. (2008). Death anxiety: A cognitive-behavioural approach. Journal of Cognitive Psychotherapy, 22, 167-182.

Gallagher, M.W., Naragon-Gainey, K., \& Brown, T.A. (2014). Perceived control is a transdiagnostic predictor of cognitive-behaviour therapy outcome for anxiety disorders. Cognitive Therapy and Research, 38, 10-22. 
Garner, D.M., Olmsted, M.P., Bohr, Y., \& Garfinkel, P.E. (1982). The Eating Attitudes Test: Psychometric features and clinical correlates. Psychological Medicine, 12, 871-878.

Giles, A.H. (1995). Death anxiety toward self and mother in clients with anorexia nervosa. Dissertation Abstracts International, Section B: The Sciences and Engineering, 56, 0522.

Gleaves, D.H., Pearson, C.A., Ambwani, S., \& Morey, L.C. (2014). Measuring eating disorder attitudes and behaviours: A reliability generalization study. Journal of Eating Disorders, 2, 6-18.

Goldenberg, J.L., Arndt, J., Hart, J., \& Brown, M. (2005). Dying to be thin: The effects of mortality salience and body mass index on restricted eating among women. Personality and Social Psychology Bulletin, 31, 1400-1412.

Goldenberg, J.L., McCoy, S.K., Pyszczynski, T., Greenberg, J., \& Solomon, S. (2000). The body as a source of self-esteem: the effect of mortality salience on identification with one's body, interest in sex, and appearance monitoring. Journal of Personality and Social Psychology, 79, 118-130

Goldenberg, J.L., Pyszczynski, T., Greenberg, J., \& Solomon, S. (2000). Fleeing the body: A terror management perspective on the problem of human corporeality. Personality and Social Psychology Review, 4, 200-218.

Goldner-Vukov, M., Moore, L.J., \& Cupina, D. (2007). Bipolar disorder: From psychoeducational to existential group therapy. Australasian Psychiatry, 15, 30-34.

Greenberg, J. (2012). Terror management theory: From genesis to revelations. In P.R. Shaver \& M. Mikulincer (Eds.), Meaning, mortality and choice: The social psychology of existential concerns (pp. 17-35). Washington D.C.: American Psychological Association.

Greenberg, J., Porteus, J., Simon, L., Pyszczynski, T., \& Solomon, S. (1995). Evidence of a terror management function of cultural icons: The effects of mortality salience on the inappropriate use of cherished cultural symbols. Personality and Social Psychology Bulletin, 21, 1221-1228.

Greenberg, J., Solomon, S., Pyszczynski, T., Rosenblatt, A., Burling, J., Lyon, D., ... Pinel, E. (1992). Why do people need self-esteem? Converging evidence that self-esteem serves an anxietybuffering function. Journal of Personality and Social Psychology, 63, 913-922.

Hayes, J., Schimel, J., Arndt, J., \& Faucher, E.H. (2010). A theoretical and empirical review of the death-thought accessibility concept in terror management research. Psychological Bulletin, 136, 699-739.

Helverskov, J.L., Clausen, L., Mors, O., Frydenberg, M., Thomsen, P.H., \& Rokkedal, K. (2010). Transdiagnostic outcome of eating disorders: A 30-month follow-up study of 629 patients. European Eating Disorders Review, 18, 453-463.

Herzog, D.B., Dorer, D.J., Keel, P.K., Selwyn, S.E., Ekeblad, E.R., Flores, A.T., ... Keller, M.B. (1999). Recovery and relapse in anorexia and bulimia nervosa: A 7.5-year follow-up study. Journal of the American Academy of Child E⿱ Adolescent Psychiatry, 38, 829-837.

Hiebert, C., Furer, P., McPhail, C., \& Walker, J.R. (2005). Death anxiety: A central feature of hypochondriasis. Depression and Anxiety, 22, 215-216.

Hope, D.A., Rapee, R.M., Heimberg, R.G., \& Dombeck, M.J. (1990). Representations of the self in social phobia: Vulnerability to social threat. Cognitive Therapy and Research, 14, 177-189.

Iverach, L., Menzies, R.G., \& Menzies, R.E. (2014). Death anxiety and its role in psychopathology: Reviewing the status of a transdiagnostic construct. Clinical Psychology Review, 34, 580-593.

Jonas, E., Greenberg, J., \& Frey, D. (2003). Connecting terror management and dissonance theory: Evidence that mortality salience increases the preference for supporting information after decisions. Personality and Social Psychology Bulletin, 29, 1181-1189.

208 Karatzias, T., Gumley, A., Power, K., \& O'Grady, M. (2007). Illness appraisals and self-esteem as correlates of anxiety and affective comorbid disorders in schizophrenia. Comprehensive Psychiatry, $48,371-375$

Kaye, W.H., Bulik, C.M., Thornton, L., Barbarich, N., Masters, K., \& Price Foundation Collaborative Group. (2004). Comorbidity of anxiety disorders with anorexia and bulimia nervosa. American Journal of Psychiatry, 161, 2215-2221.

Kellner, R., Abbott, P., Winslow, W.W., \& Pathak, D. (1987). Fears, beliefs, and attitudes in DSM-III hypochondriasis. The Journal of Nervous and Mental Disease, 175, 20-25. 
Kesebir, P. (2014). A quiet ego quiets death anxiety: Humility as an existential anxiety buffer. Journal of Personality and Social Psychology, 106, 610-623.

Kesebir, P., Luszczynska, A., Pyszczynski, T., \& Benight, C. (2011). Posttraumatic stress disorder involves disrupted anxiety-buffer mechanisms. Journal of Social and Clinical Psychology, 30, 819841.

Langdon-Brown, W., Crookshank, R., Young, J., Gordon, G., \& Bevan-Brown, C. (1931). Anorexia nervosa. London: C.W. Daniel.

Lask, B., \& Bryant-Waugh, R. (1992). Early-onset anorexia nervosa and related eating disorders. Journal of Child Psychology and Psychiatry, 33, 281-300.

Maldonado, L., Huang, Y., Chen, R., Kasen, S., Cohen, P., \& Chen, H. (2013). Impact of early adolescent anxiety disorders on self-esteem development from adolescence to young adulthood. Journal of Adolescent Health, 53, 287-292.

Maxfield, M., John, S., \& Pyszczynski, T. (2014). A terror management perspective on the role of death-related anxiety in psychological dysfunction. The Humanistic Psychologist, 42, 35-53.

McGregor, H.A., Lieberman, J.D., Greenberg, J., Solomon, S., Arndt, J., Simon, L., \& Pyszczynski, T. (1998). Terror management and aggression: Evidence that mortality salience motivates aggression against worldview-threatening others. Journal of Personality and Social Psychology, 74, 590-605.

McManus, F., Shafran, R., \& Cooper, Z. (2010). What does a transdiagnostic approach have to offer the treatment of anxiety disorders? British Journal of Clinical Psychology, 49, 491-505.

Menzies, R.G., Menzies, R.E., \& Iverach, L. (2015). The role of death fears in obsessive-compulsive disorder. Australian Clinical Psychologist, 1, 6-12.

Mitchell, J.E., \& Mussell, M.P. (1995). Comorbidity and binge eating disorder. Addictive Behaviours, $20,725-732$.

Noyes, R., Stuart, S., Longley, S.L., Langbehn, D.R., \& Happel, R.L. (2002). Hypochondriasis and fear of death. The Journal of Nervous and Mental Disease, 190, 503-509.

O'Brien, K.M., \& Vincent, N.K. (2003). Psychiatric comorbidity in anorexia and bulimia nervosa: nature, prevalence, and causal relationships. Clinical Psychology Review, 23, 57-74.

Ochsmann, R., \& Mathy, M. (1994). Depreciating of and distancing from foreigners: Effects of mortality salience. Unpublished manuscript, Universitat Mainz, Mainz, Germany.

Ongider, N., \& Eyuboglu, S.O. (2013). Investigation of death anxiety among depressive patients. Journal of Clinical Psychiatry, 16, 34-46.

Orth, U., Robins, R.W., \& Meier, L.L. (2009). Disentangling the effects of low self-esteem and stressful events on depression: findings from three longitudinal studies. Journal of Personality and Social Psychology, 97, 307-321.

Pleva, J., \& Wade, T.D. (2007). Guided self-help versus pure self-help for perfectionism: A randomised controlled trial. Behaviour Research and Therapy, 45, 849-861.

Pyszczynski, T., Greenberg, J., \& Solomon, S. (1999). A dual-process model of defense against conscious and unconscious death-related thoughts: An extension of terror management theory. Psychological Review, 106, 835-845.

Ramsawh, H.J., Raffa, S.D., Edelen, M., Rende, R., \& Keller, M.B. (2009). Anxiety in middle adulthood: Effects of age and time on the 14-year course of panic disorder, social phobia and generalized anxiety disorder. Psychological Medicine, 39, 615-624.

Randall, E. (2001). Existential therapy of panic disorder: A single system study. Clinical Social Work Journal, 29, 259-267.

Rhéaume, J., Freeston, M.H., Ladouceur, R., Bouchard, C., Gallant, L., Talbot, F., \& Vallières, A. (2000). Functional and dysfunctional perfectionists: Are they different on compulsive-like behaviours? Behaviour Research and Therapy, 38, 119-128.

Riley, C., \& Shafran, R. (2005). Clinical perfectionism: A preliminary qualitative analysis. Behavioural and Cognitive Psychotherapy, 33, 369-374.

Rosenberg, M. (1965). Society and the adolescent child. Princeton, NJ: Princeton University Press. 
Rosenblatt, A., Greenberg, J., Solomon, S., Pyszczynski, T., \& Lyon, D. (1989). Evidence for terror management theory: I. The effects of mortality salience on reactions to those who violate or uphold cultural values. Journal of Personality and Social Psychology, 57, 681-690.

Rosenvinge, J.H., Martinussen, M., \& Østensen, E. (2000). The comorbidity of eating disorders and personality disorders: A meta-analytic review of studies published between 1983 and 1998. Eating and Weight Disorders-Studies on Anorexia, Bulimia and Obesity, 5, 52-61.

Routledge, C. (2012). Failure causes fear: the effect of self-esteem threat on death-anxiety. The Journal of Social Psychology, 152, 665-669.

Royal, K.D., \& Elahi, F. (2011). Psychometric properties of the Death Anxiety Scale (DAS) among terminally ill cancer patients. Journal of Psychosocial Oncology, 29, 359-371.

Russell, J., Halasz, G., \& Beumont, P.J. (1990). Death related themes in anorexia nervosa: A practical exploration. Journal of Adolescence, 13, 311-326.

Schmitt, D.P., \& Allik, J. (2005). Simultaneous administration of the Rosenberg Self-Esteem Scale in 53 nations: Exploring the universal and culture-specific features of global self-esteem. Journal of Personality and Social Psychology, 89, 623-642.

Shaver, P.R., \& Mikulincer, M.E. (2012). Meaning, mortality, and choice: The social psychology of existential concerns. Washington, D.C.: American Psychological Association.

Simon, L., Greenberg, J., Harmon-Jones, E., Solomon, S., Pyszczynski, T., Arndt, J., \& Abend, T. (1996). Mild depression, mortality salience and defense of the worldview evidence of intensified terror management in the mildly depressed. Personality and Social Psychology Bulletin, 22, 81-90.

Sinclair, S.J., Blais, M.A., Gansler, D.A., Sandberg, E., Bistis, K., \& LoCicero, A. (2010). Psychometric properties of the Rosenberg Self-Esteem Scale: Overall and across demographic groups living within the United States. Evaluation $\mathcal{E}$ the Health Professions, 33, 56-80.

Slade, P. (1982). Towards a functional analysis of anorexia nervosa and bulimia nervosa. British Journal of Clinical Psychology, 21, 167-179.

Slaney, R.B., Rice, K.G., Mobley, M., Trippi, J., \& Ashby, J.S. (2001). The revised Almost Perfect Scale. Measurement and Evaluation in Counselling and Development, 34, 130-145.

Solomon, S., Greenberg, J., \& Pyszczynski, T. (2004). The cultural animal. In J. Greenberg, S.L. Koole \& T. Pyszczynski (Eds.), Handbook of experimental existential psychology (pp. 13-34). New York, NY: Guilford Publications.

Southgate, L., Tchanturia, K., Collier, D., \& Treasure, J. (2008). The development of the childhood retrospective perfectionism questionnaire (CHIRP) in an eating disorder sample. European Eating Disorders Review, 16, 451-462.

Sowislo, J.F., Orth, U., \& Meier, L.L. (2014). What constitutes vulnerable self-esteem? Comparing the prospective effects of low, unstable, and contingent self-esteem on depressive symptoms. Journal of Abnormal Psychology, 123, 737-753.

Stålsett, G., Gude, T., Rønnestad, M.H., \& Monsen, J.T. (2012). Existential dynamic therapy ('VITA') for treatment-resistant depression with Cluster C disorder: Matched comparison to treatment as usual. Psychotherapy Research, 22, 579-591.

Starcevic, V. (2005). Fear of death in hypochondriasis: Bodily threat and its treatment implications. Journal of Contemporary Psychotherapy, 35, 227-237.

St Clare, T., Menzies, R.G., \& Jones, M.K. (2008). Danger Ideation Reduction Therapy (DIRT) for obsessive-compulsive washers: A comprehensive guide to treatment. Brisbane, Australia: Australian Academic Press.

210 Steele, A.L., Corsini, N., \& Wade, T.D. (2007). The interaction of perfectionism, perceived weight status, and self-esteem to predict bulimic symptoms: The role of 'benign' perfectionism. Behaviour Research and Therapy, 45, 1647-1655.

Steele, A.L., \& Wade, T.D. (2008). A randomised trial investigating guided self-help to reduce perfectionism and its impact on bulimia nervosa: A pilot study. Behaviour Research and Therapy, 46, 1316-1323.

Steinhausen, H.C. (2009). Outcome of eating disorders. Child and Adolescent Psychiatric Clinics of North America, 18, 225-242. 
Strachan, E., Pyszczynski, T., Greenberg, J., \& Solomon, S. (2001). Coping with the inevitability of death: Terror management and mismanagement. In C.R. Snyder (Ed.), Coping with stress: Effective people and processes (pp. 114-136). New York, NY: Oxford University Press.

Strachan, E., Schimel, J., Arndt, J., Williams, T., Solomon, S., Pyszczynski, T., \& Greenberg, J. (2007). Terror mismanagement: Evidence that mortality salience exacerbates phobic and compulsive behaviours. Personality and Social Psychology Bulletin, 33, 1137-1151.

Striegel-Moore, R.H., Rosselli, F., Perrin, N., DeBar, L., Wilson, G.T., May, A., \& Kraemer, H.C. (2009). Gender difference in the prevalence of eating disorder symptoms. International Journal of Eating Disorders, 42, 471-474.

Tabachnick, B.G., \& Fidell, L.S. (2014). Using multivariate statistics (6th ed.). Harlow, England: Pearson Education Limited.

Taubman Ben-Ari, O., Florian, V., \& Mikulincer, M. (1999). The impact of mortality salience on reckless driving: A test of terror management mechanisms. Journal of Personality and Social Psychology, 76, 35-45.

Teachman, B.A., Marker, C.D., \& Clerkin, E.M. (2010). Catastrophic misinterpretations as a predictor of symptom change during treatment for panic disorder. Journal of Consulting and Clinical Psychology, 78, 964-973.

Templer, D.I. (1970). The construction and validation of a death anxiety scale. The Journal of General Psychology, 82, 165-177.

Tomás-Sábado, J., \& Gómez-Benito, J. (2002). Psychometric properties of the Spanish form of Templer's Death Anxiety Scale. Psychological Reports, 91, 1116-1120.

Torrey, W.C., Mueser, K.T., McHugo, G.H., \& Drake, R.E. (2014). Self-esteem as an outcome measure in studies of vocational rehabilitation for adults with severe mental illness. Psychiatric Services, 51, 229-233.

Turner, H., Marshall, E., Stopa, L., \& Waller, G. (2015). Cognitive-behavioural therapy for outpatients with eating disorders: Effectiveness for a transdiagnostic group in a routine clinical setting. Behaviour Research and Therapy, 68, 70-75.

Vaccaro, L., Jones, M.K., Menzies, R.G., \& St Clare, T. (2010). Danger Ideation Reduction Therapy (DIRT) for obsessive-compulsive checkers: A comprehensive guide to treatment. Brisbane, Australia: Australian Academic Press.

Yalom, I.D. (2008). Staring at the sun: Overcoming the terror of death. The Humanistic Psychologist, $36,283-297$. 